\title{
Definition of tailor made cutting tools for machining of complex surfaces based on final surface shape
}

\author{
Gaizka Gómez Escudero \\ Department of Mechanical Engineering \\ University of the Basque Country \\ (UPV/EHU) \\ Bilbao, Spain \\ gaizka.gomez@ehu.eus
}

\author{
Luis Norberto López de Lacalle \\ Marcaide \\ Advance Manufacturing Center for \\ Aeronautics (CFAA) \\ University of the Basque Country \\ (UPV/EHU) \\ Zamudio, Spain \\ norberto.lzlacalle@ehu.eus
}

\author{
Pablo Fernández De Lucio \\ Department of Mechanical Engineering \\ University of the Basque Country \\ (UPV/EHU) \\ Bilbao, Spain \\ pablo.fernandezd@ehu.eus
}

Amaia Calleja Ochoa

Department of Mechanical Engineering

University of the Basque Country

(UPV/EHU)

Vitoria, Spain

amaia.calleja@ehu.eus

\author{
Haizea González Barrio \\ Department of Mechanical Engineering \\ University of the Basque Country \\ (UPV/EHU) \\ Bilbao, Spain \\ haizea.gonzalez@ehu.eus
}

\author{
Michael Barton \\ Basque Center for Applied \\ Mathematics (BCAM) \\ Bilbao, Spain \\ mbarton@bcamath.org
}

\begin{abstract}
In this work a design methodology to define the best geometry of cutting tool for complex surfaces is defined, being based on the final part surface geometry. The manufacture of components with tailor made shaped tools, based on algorithm calculation and adapted to the geometry of the final piece surface, reduces manufacturing time and maintains piece quality in comparison with traditional cutting tools. Cutting tools are usually cylindrical (end mills) or ball-end mills. With mathematical algorithms can be defined diamond \& CBN electroplated form tools, multi-tooth endmills, abrasive grinding tools and so on. The approach here presented can enable the production of tools for manufacturing process such as Super Abrasive Machining (SAM) and Flank milling strategies. Comparison between standard tools and traditional machining processes versus custom-shaped tools was studied in terms of process time. Final applications are numerous, such as, integral blade rotors, spiral bevel gears, blisks and impellers, complex screws, and others.
\end{abstract}

Keywords - Tailor made cutting tools; form tool; SAM (Super Abrasive Machining), five-axis milling.

\section{INTRODUCTION}

One of the prime objectives of industry is productivity, and efficiency improvement. In order to carry through this objective, manufacturing processes need to be optimized. There is a continuous search of new manufacturing processes that will reduce manufacturing time and cost. In this line, Super Abrasive Machining (SAM) is one of the last emerging processes that aims at accomplishing these two goals. SAM is based on the use of grinding technology maintaining machining feeds and speeds. Moreover, grinding precision values are also maintained for high material removal rates at high speed [1] and near shape surfaces. It is also possible to obtain high removal rates for finishing grinding operations. SAM technology has been tested for aeronautic complex geometries such as blades from IBRs or impellers. Companies such as Rolls-Royce state that, under the optimum cutting conditions, SAM process is able to obtain a removal rate of 80 cubic millimetres per second per millimetre of wheel width [2]. This value is eight times the rate that can be reached using plated CBN wheel technology for SAM process in nickel alloys on a conventional grinding machine. Moreover, SAM process has some advantages over single point machining process [3], such as simpler tool designs, more robust tools, lower tool maintenance and elimination of post machining distortion.

Regarding machining strategies, standard milling/grinding strategies manually programmed or CAM based can be performed [4]. However, optimized strategies can be obtained based on the optimization of tool positioning trajectories and tool geometry. Some algorithms focus on the optimization of cylindrical tool positioning in ruled surfaces [5], these types of surfaces are generated by the motion of a ruling along two guides. In these algorithms the given geometry is divided into small patches that match according to a given tool geometry. Some other algorithms are developed for conical tools, in order to perform flank milling strategies on ruled surfaces [6]. Nowadays, developed algorithms calculate both the optimal geometry of the tool and the machining trajectories, therefore flank milling operation can be performed on non-ruled surfaces. Reference [7] Developed an algorithm that computes the optimal shape of a general rotational tool and its motion in $3 \mathrm{D}$ space, in such a way that the corresponding envelope approximates the input surface geometry within a high accuracy, between a preestablished error values.

The tools that are used in SAM machining operations are electroplated tools, that are reusable after a flaking process, followed by a re-electroplating operation. The use of this type of tools entails a saving in the cost of tools. They have been generally used in turning/grinding operations in a wide range of applications in the automotive, optical [8] and communication industry as well as in medical and life science in order to obtain ultraprecision components. Nowadays, electroplated milling tools are studied for drilling [9] and milling [10] applications. An electroplated milling tool consists of a steel core and a single or multi-layer of abrasive grains in the cutting area. It is noteworthy when using diamond \& CBN electroplated tools, owing to hightemperature cutting conditions, are required cutting fluids, in this case are more advisable cutting oils [11-13]. With regard to cutting conditions, as it is mentioned in [14], they can be optimized in order to develop exact cutting parameters ranges. Furthermore, one consideration that should be taken into account is that the machines requires high speed spindles $(60,000-90,000 \mathrm{rpm})$ [15], that in his majority is unattainable for the most modern machining centres, whose spindle capacities reach only $20,000 \mathrm{rpm}$. In relation to tool geometry, 
the design of diamond \& CBN electroplated form tools for free-form surfaces machining will include all the advantages related to time reduction, cost reduction and surface quality.

Other aspect that does not vary in the course of the industry is the use of gear, for example, the use of spiral bevel gears in applications [16] with requirements of silent power transmissions and smoothness, this is the case of ship propulsion systems, thermal energy generation or in the aeroengine components. Nowadays, the demand in the energy consumption is in a growing tendency, hence the need of thermal generation components too, e.g. spiral bevel gears. For the manufacturing of gears have been used special machined developed by different companies. Regarding to this, there are many methods for the tooth surface generation. The most extended ones are the following ones: Gleason's gearing, Klingelnberg's Palloid System, and the Oerlikon's and Klingelnberg's Palloid System. In the last years there have been many researches about the manufacturing of gears in multitasking machines [17] with standard tools [18]. This work goes in the direction of using simpler tools for the manufacturing of gears, enabling the production of complex surfaces using non-dedicated machines.

Therefore, in this work, the design and manufacturing of a form tool to be applied for the manufacturing of a spiral bevel gear teeth through Flank SAM is presented, as an alternative to the gears manufacturing methods mentioned above. In concrete, tool geometry design, tool core manufacturing and electroplated process for final abrasive tool generation. Time comparison between standard tools and traditional machining processes versus form tools for SAM is also included.

\section{TOOL DESIGN PROCESS}

The design method is presented in the flowcharts given in Fig. 1. As shown, the first step is the analysis of current surface definition, in order to see any surface pattern, present in the target surfaces. Depending the surface pattern, concretely if it is a non-ruled or non-developable surface it will require some geometrical modifications in order to perform flank milling strategies. In contrast, if the surface is ruled or developable it will not be modified.

The second step is the modification of surfaces if a dramatic change in machining time can be achieved by a little modification of the surface geometry within an admissible error value. The third step is the determination if double flank contact can be followed in machining, this is the case of the gears, that could be manufactured both sides of the cavity of each tooth with just one path. The fourth step is the definition of the application for which the tool will be used, for example abrasive grinding tool, diamond \& $\mathrm{CBN}$ electroplated form tool or multi-tooth endmill tool among others.

The final step is the generation of the geometry of the tool according to the characteristic above.

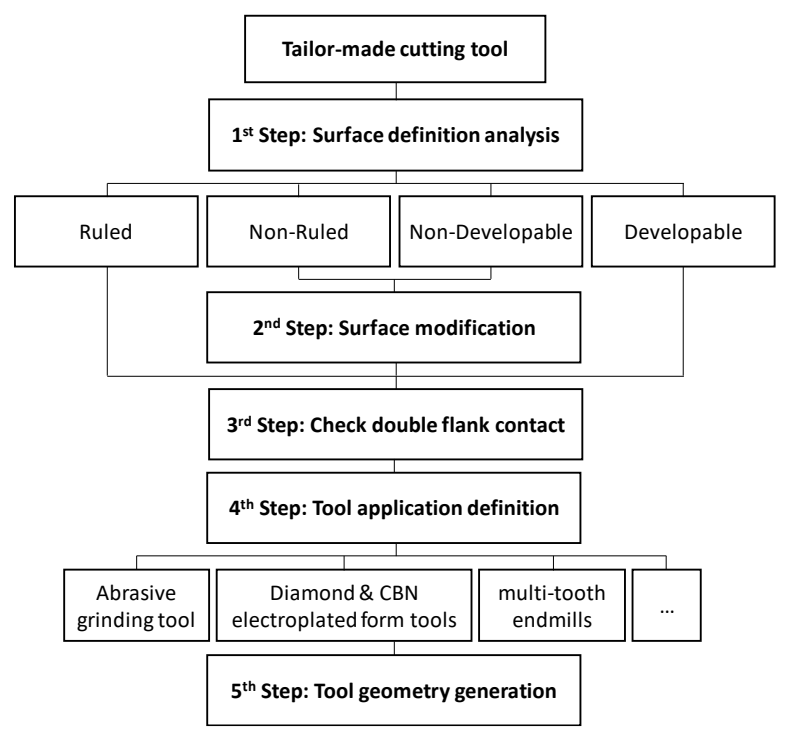

Fig. 1. Tailor-made cutting tool flowchart

An example of new tailor-made-tools adapted according to a part geometry is shown in Table I. This is the case of spiral bevel gears, which are key for large rotary tables and positioning systems.

In this case study, in spiral bevel gears can be performed double flank contact, and this will allows obtaining better smoothness in the surface quality, because both sides of the tooth cavity are manufactured at the same time.

After an initial roughing operation, designed form tool will perform the semi-finishing and finishing operation, both at the same time. The tool is designed according to an algorithm [19] that looks for optimal milling paths and optimal tool shape.

TABLE I. Main geometrical parameters of case study: spiral bevel gear

\begin{tabular}{lc}
\hline \multicolumn{2}{c}{ Spiral bevel gear parameters } \\
\hline Heel pitch diameter $(D p)$ & $200 \mathrm{~mm}$ \\
Outside diameter $(D e)$ & $207.6 \mathrm{~mm}$ \\
Number of teeth $(\mathrm{Z})$ & 25 \\
Spiral angle $(\beta)$ & $35^{\circ}$ \\
Face angle & $59.5^{\circ}$ \\
Pressure angle $(\alpha)$ & $20^{\circ}$ \\
\hline
\end{tabular}

\section{TOOL MANUFACTURING PROCESS}

Every manufacturing process implies the need of a tool, in this case, a custom shaped tool will be manufactured adapted to the final geometry of the part. Cutting tools will include two stages, firstly the manufacturing of the tool shank, on which the teeth (regular machining, or defined-cutting edge approach) or abrasive particles (abrasive process, non-defined cutting-edge approach) must be produced in a subsequent operation. 


\section{A. Tool shank manufacturing}

The only materials that can be easily electroplated with diamond \& CBN are exclusively steel, aluminium or nonferrous cores. In this case, AISI 1055 is selected for tool core manufacturing. The reason to select AISI 1055 is because it is a material in which the abrasive grains can be easily electroplated according to companies in the tooling sector. Mechanical and thermal properties are shown in Table II, with interest because in abrasive cases the tool heating is the main cause of tool shank breakage.

TABLE II. Mechanical and thermal properties of AISI 1055 taken from standard

\begin{tabular}{cc}
\hline Property & Values \\
\hline Density $(\mathrm{g} / \mathrm{cm} 3)$ & 7.85 \\
Thermal conductivity $(\mathrm{W} / \mathrm{m} \mathrm{K})$ & 49.8 \\
Specific heat $(\mathrm{J} / \mathrm{g} \mathrm{K})$ & 0.472 \\
Vickers hardness & 207 \\
Melting point $\left({ }^{\circ} \mathrm{C}\right)$ & 1460 \\
Elasticity modulus $(\mathrm{GPa})$ & $190-210$ \\
Tensile strength, yield $(\mathrm{MPa})$ & 560 \\
Tensile strength, ultimate $(\mathrm{MPa})$ & 660 \\
\hline
\end{tabular}

The manufacturing of the tool core was carried out on AISI 1055 steel in CNC turning centre. The lathe is equipped with four axes, three of them linear $\mathrm{X}, \mathrm{Y}$ and $\mathrm{Z}$ and one rotary $\mathrm{C}$. The clamping of the initial billet was done with a three-jaw chuck and without a counterpoint due to the small diameter of the tool. The key aspect of the lathe to be used is that the compact electro spindle, which keeps runout in values below 3 micrometres. The tool holder is placed on a dynamometric table.

To manufacture the core of the tool, a cylindrical billet of $40 \mathrm{~mm}$ of diameter was used. In it, three different types of operations are defined. The first operation is a roughing operation in order to eliminate non needed amount of material, then a semi-finishing operation is performed to obtain near to net shape geometry with different cutting conditions, and finally a finishing operation to get the designed geometry of the tool. Cutting conditions of each operation are shown in Table III. External coolant is used for lubrication during the operations.

TABLE III. Cutting parameters of turning operations

\begin{tabular}{cccc}
\hline Parameter & Roughing & $\begin{array}{c}\text { Semi- } \\
\text { finishing }\end{array}$ & Finishing \\
\hline $\begin{array}{c}\text { Cutting speed } \\
V_{c}(\mathrm{~m} / \mathrm{min})\end{array}$ & 190 & 300 & 300 \\
$\begin{array}{c}\text { Feed } \\
f(\mathrm{~mm} / \mathrm{rev})\end{array}$ & 0.4 & 0.2 & 0.2 \\
$\begin{array}{c}\text { Cutting depth } \\
a_{p}(\mathrm{~mm})\end{array}$ & 2 & 1 & 0.5 \\
Number of steps & 5 & 7 & 1 \\
\hline
\end{tabular}

The programming of the roughing operation is done manually; the removed material does not affect the final geometry. On the other hand, trajectories for both semifinishing and finishing processes are programmed with CAM software, using the software Siemens NX12.

In the roughing operation the objective is to remove the material in a quick way without considering surface quality. In this case a square roughing insert is used with this denomination CNMG 12-04-12-PR 4225 (Sandvik Coromant $\left({ }^{\circledR}\right)$. With this insert, five roughing turning passes are made with a depth of cut of $2 \mathrm{~mm}$, decreasing the initial diameter of the billet from 40 to 20 millimetres.
In the semi-finishing operation, the rest of material is removed with more conservative cutting conditions in order to obtain lower cutting forces. The diameter of the final tool is too small, around $6 \mathrm{~mm}$, therefore a finishing rhombic insert was used with this denomination VBMT 1604 08-PR 4225 (Sandvik Coromant $\left.{ }^{\circledR}\right)$. Once this operation is performed, there is a stock of $0.5 \mathrm{~mm}$ left for the finishing operation.

Finally, a finishing pass is performed to obtain the final geometry of the tool core, see Fig. 2. In this operation the rhombic insert is also used, but with a smaller depth of cut, in this case $0.5 \mathrm{~mm}$.



Fig. 2. Form tool geometry for SAM: blueprint on the left and custom shape tool shank manufactured on the rigth

\section{B. Diamond \& CBN electroplating process}

In order to manufacture electroplated diamond and $\mathrm{CBN}$ tools there are some base materials between which must be chosen for the shank manufacturing core. The shank material must be exclusively steel, aluminium or non-ferrous materials. The latter two it is only used in exceptional situations. Prior to the electroplating process, tools must be inserted in special containers, in which the contact is established using jigs or brass bushings. Before starting the process must be determined the area that it is going to be electroplated, and the rest of the surface area exposed to the process is masked using lacquers, self-adhesive tapes or plastic-jigs.

Once both the electroplated area and the rest are calculated the electroplating process itself takes place. Firstly, initial mechanical cleaning it is made in order to remove impurities. Then, electroplating pre-treatment it is made in a several electrolyte baths in order to obtain the correct adhesions between the abrasive material and tool core. After that, the tool that it is going to be electroplated it is inserted in the containers mentioned above. After, the tool it is connected to electricity and the jig it is filled with the abrasive material. Before starting the electroplating process, the parameters of the rectifier are stablished to the correct current output. Finally, the electroplating process begins.

After a certain period of time determine by the electroplating process, the abrasive grains start to get bond into the tool core. During this process, the tool must be turned and the jigs must be refilled with abrasive material. Afterwards, the tool it is taken out from the container and it is introduced in a nickel bath to complete the process. The thickness of the coating depends on the abrasive grain size and the application in which it is going to be used the tool.

\section{TIME AnALYSIS}

In this section, the comparison between standard milling tools and designed diamond \& CBN electroplated form a tool regarding to time is carried out. In relation to time analysis, in both cases the studied operation is the semi-finishing operation. In the case of milling operation with standard tools, point milling operation is required. Zig-Zag pattern with $0.002 \mathrm{~mm}$ scallop requires around 10 minutes. The 
manufacturing process time of this operation has been obtained using a conical mill with 3 flutes with a diameter of $2 \mathrm{~mm}$ and with a tapper angle of $8^{\circ}$, the cutting conditions were the following ones: feed per tooth (fz) of $0.02 \mathrm{~mm} / \mathrm{tooth}$, cutting speed $(\mathrm{Vc})$ of $72 \mathrm{~m} / \mathrm{min}$. Point milling operation includes multiple passes until the surface is milled. In the case of FSAM machining with custom shape tool, there is only one pass needed. In this case, the required time is around $3 \mathrm{sec}$. The manufacturing process time of this operation has been obtained using a SAM tool with a variable diameter that goes from $13.2 \mathrm{~mm}$ to $4.8 \mathrm{~mm}$, see Fig. 2, the cutting conditions were the following ones: feed $(\mathrm{F})$ of $500 \mathrm{~mm} / \mathrm{min}$ and cutting speed $(\mathrm{Vc})$ of $900 \mathrm{~m} / \mathrm{min}$.

\section{CONCLUSIONS}

This work presents a methodology to define the best geometry of cutting tool for complex surfaces, being based on the final part surface complex form. It mainly focused on the manufacturing process of a SAM tool core that will be used in the semi-finishing and finishing operations of a spiral bevel gear manufacturing. In first place, the tool geometry has been designed according to the described methodology presented in the Fig. 1, which according to a mathematic algorithm that, given the bevel gear as the input reference geometry, computes an optimal shape of the tool and its path to best approximate the input surface to be flank-milled. Major conclusions from this work can be summarized, concerning the manufacturing process of a SAM tool, as given below:

- In diamond \& CBN electroplated tools, the abrasive grains protrude from the base matrix, so it leads to a more effective material removal rate because the matrix gets intact while the grains remove material. In this way, least heat generation it is made during the process and it implies an enhance of the efficiency of tool's life.

- Electroplated tools are widely used in grinding operations because the abrasive grains are less likely to fall due to the high strength of an electroplated plating layer. So, it is reasonable to think about the use of this technology in semi- and finishing operations, for example the manufacturing of spiral bevel gears teeth.

- Finally, one of the most relevant aspects in the industry is the manufacturing time. With the implementation of SAM tool in the semi-finishing and finishing operations in gears manufacturing will lead to a significant reduction of machining time, in the studied case, the semi-finishing operation of a spiral bevel gear tooth is 100 times faster with a SAM tool.

Therefore, the use of SAM tools together with flank milling strategies is presented as a new alternative for the manufacturing of gears. Moreover, it is process that combines the benefits from milling and grinding technologies.

\section{ACKNOWLEDGMENT}

This project has received funding from the European Union's Horizon 2020 research and innovation programme under grant agreement No 862025

\section{REFERENCES}

[1] C. Guo, S. Ranganath, D. McIntosh, A. Elfizy. "Virtual high performance grinding with CBN wheels," in CIRP Annals, Manufacturing Technology, vol 57, pp. 325-328, 2008.

[2] Radical Departures. Available online: https://www.radicaldepartures.net/articles/flexible-grinding-no-grinder-required/ (accessed on 10 Marz 2020).

[3] R. Petrilli. "Super abrasive machining for PM," in Metal Powder Report, vol 64, pp. 38-41, 2012.

[4] F. Klocke, M. Brumm, J. Staudt. "Quality and surface of gears manufactured by free form milling with standard tools," in Procedia of the International Gear Conference, Lyon, France, 26-28, pp. 26-28, August 2014.

[5] H. Gong, L.X. Cao, L. Jian. "Improved positioning of cylindrical cutter for flank milling ruled surfaces," in Computer Aided Design, vol 37, pp. 1205-1213, 2005.

[6] Y.A. Lu, Q.Z. Bi, L.M. Zhu. "Five-axis flank milling of impellers: Optimal geometry of a conical tool considering stiffness and geometric constraints," in Proceedings of the Institution of Mechanical Engineers, Part B: Journal of Engineering Manufacture, vol 230, pp. 38-52, 2016.

[7] P. Bo, M. Barton, H. Pottmann. "Automatic fitting of conical envelopes to free-form surfaces for flank CNC machining," in Computer Aided Design, vol 91, pp. 84-94, 2017.

[8] D.J. Stephenson, X. Sun,C. Zervos. “A study on ELID ultra precision grinding of optical glass with acoustic emission," in. International Journal. of Machining Tools and Manufacturing, vol 46, pp. 10531063, 2006.

[9] D. Biermann, T. Bathe, C. Rautert. "Core Drilling of Fiber Reinforced Materials using Abrasive Tools," in Procedia CIRP, vol 66, pp. 175$180,2017$.

[10] H. Gonzalez, A. Calleja, O. Pereira, N. Ortega, L.N. Lopez de Lacalle, M. Barton. "Super Abrasive Machining of Integral Rotary Components Using Grinding Flank Tools,” in MDPI-Metals, vol 8, pp. 1-24, 2018.

[11] M.K. Sinha, R. Madarkar, S. Ghosh, P.V. Vao. "Application of ecofriendly nanofluids during grinding of Inconel 718 through small quantity lubrication," in Journal Cleaner Production, vol 141, pp. 1359-1375, 2017.

[12] O. Pereira, G. Urbikain, A. Rodriguez, A. Fernandez-Valdivielso, A. Calleja, I. Ayesta, L.N. Lopez de Lacalle. "Internal cryolubrication approach for Inconel 718 milling," in Procedia Manufacturing, vol 13, pp. 89-93, 2017.

[13] A. Caggiano, R. Teti. "CBN grinding performance improvement in aircraft engine components manufacture," in Procedia CIRP, vol 9, pp. 109-114, 2009.

[14] L.N. López de Lacalle, A. Lamikiz, J.A. Sánchez, I. Cabanes. "Cutting conditions and tool optimization in the high-speed milling of aluminium alloys," in Proceedings of the Institution of Mechanical Engineers Part B Journal of Engineering Manufacture, vol 215, pp. 1257-1269, 2001.

[15] D.K. Aspinwall, S.L. Soo, D.T. Curtis, A.L. Mantle. "Profiled superabrasive grinding wheels for themachining of a nickel based superalloy," in CIRP Annals Manufacturing Technology, vol 56, pp. 335-338, 2007.

[16] X. Hu, Y. Jiang, C. Luo, L. Feng, Y. Dai. "Churning power losses of a gearbox with spiral bevel geared transmission," in Tribology International, vol 129, pp. 398-406, 2019.

[17] K. Kawasaki, I. Tsuji, Y. Abe, H. Gunbara. "Manufacturing method of large-sized spiral bevel gears in cyclo-palloid system using multi-axis control and multi-tasking machine tool," iIn Procedia of the International Conference on Gears, Garching, Germany, pp. 56-61, 46 October 2010.

[18] Y.P. Shih, Z.H. Sun, F.C. Wu. "A disk tool cutting method for bevel gear manufacture on a five-axis machine," in International Journal of Advanced Manufacturing Technology, vol 94, pp. 855-865, 2018.

[19] A. Calleja, P. Bo, H. Gonzalez , M. Barton, L.N. López de Lacalle. "Highly accurate 5-axis flank CNC machining with conical tools," in The International Journal of Advanced Manufacturing Technology, vol 97, pp 1605-1615, 2018. 